\title{
MOSTRA CULTURAL COMO ESTRATÉGIA DE DIVULGAÇÃO CIENTÍFICA NA ESCOLA PÚBLICA DE ENSINO FUNDAMENTAL: UMA MANEIRA DE SUPERAÇÃO DA NEUTRALIDADE DA CIÊNCIA
}

\author{
Leonardo Salvalaio Muline ${ }^{1}$, Adriane Gonçalves Gomes ${ }^{2}$, Carlos Roberto Pires Campos ${ }^{3}$
}

\author{
Programa de Pós-graduação em Educação em Ciências e Matemática \\ Instituto Federal do Espírito Santo - Campus Vitória \\ Avenida Vitória, 1729 - Jucutuquara, Vitória, Espírito Santo. CEP 29040780.
}

\section{RESUMO}

A presente pesquisa qualitativa, do tipo etnografia escolar, teve como objetivo analisar o potencial pedagógico de uma Mostra Cultural realizada em 2011 na Escola Municipal de Ensino Fundamental Marieta Escobar, localizada no município de Vitória, do Estado do Espírito Santo. Na coleta de dados, adotamos uma postura de observação participante e sistemática dos procedimentos, durante a apresentação dos trabalhos e na fase de sua confecção. Vale destacar que a investigação discute o papel social dentro do contexto escolar, não ignorando as múltiplas implicações que tal processo desencadeia. Acreditamos que, a partir da Mostra Cultural, é possível superar o paradigma de que a ciência é para poucos e que o cientista é aquele indivíduo inatingível, cuja formação poucos conseguirão atingir.

Palavras-chave: ensino de ciências, divulgação científica, mostra cultural.

\section{ABSTRACT}

This qualitative ethnographic research aimed to analyze the pedagogical potential of a cultural exposition held in 2011 at a Municipal Elementary School Marieta Escobar, located in Vitória, state of Espírito Santo. For collecting data, we adopt a participant observation perspective and systematic procedures both during the presentation of the work and the in stage of its preparation. It is worth noting that the research discusses the social role within the school context, not ignoring the multiple implications that this process triggers. We believe that, with the cultural exposition, it is possible to overcome the paradigm that science is not for everyone and that the scientist is an unattainable one, whose formation a few manage to reach.

Keywords: science education, scientific difusion, cultural exposition of science .

\footnotetext{
1 Professor de Ciências Biológicas do Instituto Federal Fluminense, Campus Macaé. Mestre em Educação em Ciências e Matemática - E-mail: leonardosalvalaio@gmail.com

2 Professora de História da Rede Estadual de Educação Básica, Espírito Santo. Mestre em Educação em Ciências e Matemática.E-mail: adrianegoncalvesgomes@yahoo.com.br

3 Professor de Ensino de Letras do Instituto Federal do Espírito Santo, D.L. - Docente do Programa de Pósgraduação em Educação em Ciências e Matemática do Ifes. E-mail: carlosr@ifes.edu.br
} 


\section{INTRODUÇÃO}

A divulgação da ciência, como tema de interesse de pesquisa, vem sendo objeto de constantes estudos, recebendo variados enfoques de tratamento, tais como sociologia da ciência, popularização da ciência e interfaces entre ciência e público, a depender do pesquisador e da finalidade que defende. 0 importante é que todos, de um modo geral, se preocupam com o grande vácuo que existe entre o que é produzido pela academia e o que chega até o público. Isso é facilmente perceptível em fatos corriqueiros para a academia, os quais, para o público, se configuram como verdadeiros enigmas, tais como que a terra se move em torno do sol, que uma bússola sempre aponta para o norte e que a estrutura do DNA carrega nossa herança genética. Se perguntarmos isso aos muitos pais de alunos da Educação Básica, não vão ser tão objetivas as respostas quanto para um aluno de sexto ano do Ensino Fundamental. A ignorância do público sobre fatos fundamentais da ciência, mesmo em países de primeiro mundo, é surpreendente (AUGUSTINE, 1988). Ocorre que a realidade da ciência, para a maior parte do público, é a apresentada pelos meios de comunicação de massa. 0 público geral não conhece a ciência por experiência direta, por participação em eventos científicos ou por atividades de voluntariados em desenvolvimento de pesquisas acadêmicas. É a mídia o canal que leva ao público os resultados, e quantas vezes estes não são tendenciosos?, das pesquisas cientificas. Até mesmo dentro das escolas, a realidade da ciência é centrada no estudo dos manuais didáticos. Basta uma rápida incursão a algumas escolas para chegarmos à realidade que muitos alunos nunca manipularam uma lamina ou uma lamínula em um laboratório de ciências para conhecer a estrutura de uma célula vegetal ou animal. Muitos nunca executaram um experimento básico dentro do campo do conhecimento científico, muitos nunca participaram de uma aula de campo orientada, com produção de relatório. Os computadores chegaram às escolas antes dos microscópios.

A transmissão intencional e formal do conhecimento científico, para o leigo, configura-se como uma tarefa atormentada por vários obstáculos, um deles é apresentar o fato científico em oposição ao senso comum e à visão concreta dos objetos e fatos (EPSTEIN, 2002). Uma outra forma de socializar a ciência seria por meio da modificação do discurso linguístico retórico de modo a facilitar a compreensão, o que recebe, todavia, muitas críticas por parte da academia. 
Para Vogt (2011), o conjunto de fatores, eventos e ações humanas nos processos sociais direcionados para a produção, a difusão, o ensino e a divulgação do conhecimento científico constitui os pressupostos para o desenvolvimento de um tipo especial de cultura, qual seja, a cultura científica, que pode ser compreendida a partir de três sentidos, quais sejam, "a cultura da ciência", a "cultura pela ciência" e a "cultura para a ciência", sobre esta última, deteremos a discussão por um pouco mais tempo.

A compreensão da difusão científica implica considerar que esta comporia a "cultura para a ciência", (VOGT, 2011) fazendo parte do processo de educação, de modo a favorecer a apropriação da ciência e da tecnologia por parte da sociedade. É preciso compreendermos que existe uma forte ligação entre ciência e cultura e a ciência precisa se tornar uma prática cultural, se desejarmos construir cidadãos emancipados e autônomos. A dinâmica constitutiva da cultura compreende, dentro de si, a ciência e esta entra como fundamento daquela na constituição da identidade cultural dos atores sociais. Contribuem para este fim, no âmbito escolar, os eventos, as feiras de ciências, os jornais escolares da ciência, os painéis da ciência, murais de divulgação, as revistas à disposição dos alunos e da comunidade, todos, enfim, possuem papel preponderante na mobilização da sociedade para o despertar do "amor pela ciência e pelo conhecimento (VOGT, 2011 p. 13). Assim, essas experiências de divulgação da ciência têm por objetivo fazer com que a ciência seja vivenciada e experiência por um número sempre maior de cidadãos. Não é preciso ser cientista para amar a ciência, assim como não é preciso ser poeta para amar a poesia, nem é preciso ser romântico para gostar da natureza. A mesma paixão que move a inclinação pela natureza e pela cultura deve mover o homem para o amor à ciência. A participação crítica, a participação no debate político, a mobilização do Estado em favor da elaboração de políticas públicas para combater a ignorância científica da população e para preservar o meio ambiente, a busca pela paz social, a busca pelo bem estar social, tudo, pressupõe conhecimento das bases da ciência. Como um cidadão pode opinar em relação ao Protocolo de Kyoto sem saber do que se trata ou como pode dar sua opinião sobre os transgênicos se não conhece as artimanhas do melhoramento genético de plantas? Para Vogt (2011), o bem estar cultural apresenta-se como um conceito e um estado de espírito cuja característica aponta para o conforto crítico da inquietude decorrente das provocações sistemáticas do conhecimento. 
Eis, pois, o horizonte deste trabalho, apontar a mostra cultural nas escolas como espaço propício de divulgação da ciência, de formação de opiniões e de participação da comunidade escolar nos debates sobre o conhecimento científico e cultural.

\section{PROCEDIMENTOS METODOLÓGICOS}

\section{A pesquisa}

Pesquisa de natureza qualitativa, do tipo etnografia escolar, que propõe apresentar e analisar os processos e os efeitos de uma atividade desenvolvida durante a Mostra Cultural 2011 da Escola Municipal de Ensino Fundamental Marieta Escobar como atividade para discutir a História da Ciência, foi baseada nos pressupostos alfabetização científica, por meio de um estudo de caso (LUDKE; ANDRÉ, 1986). Na coleta de dados, adotamos uma postura de observação participante e sistemática dos procedimentos, tanto durante a apresentação dos trabalhos quanto na confecção dos mesmos; a análise dos conteúdos foi baseada em Bardin (2004).

\section{Local}

A escola onde foi realizada a Mostra Cultural fica localizada no bairro Santa Martha, em Vitória (ES). Atende a alunos do primeiro ano do ensino fundamental até educandos do nono ano do ensino fundamental. Pertence à rede municipal de ensino de Vitória, capital do Estado. Funciona nos turnos matutino e vespertino e fica localizada no ambiente urbano, próximo de muitas residências e de um comércio bastante movimentado. Além disso, recebe alunos de diversas classes sociais, predominando crianças de pouco poder econômico.

\section{Sujeitos}

A turma analisada possui um total de 27 alunos frequentando regularmente as aulas, sendo que 62,96\% dos discentes são do gênero feminino e 37,04\% são do masculino. A faixa etária dos educandos da turma analisada variou dos 13 aos 16 anos de idade. Vale ressaltar que toda a turma ficou envolvida na confecção dos materiais para a divulgação no dia da culminância da Mostra Cultural, entretanto, no dia marcado, somente 17 educandos se revezaram na exposição e explicação das atividades realizadas para a comunidade escolar. 


\section{Coleta de Dados}

Foram feitas observações dos educandos durante a realização das atividades, e a análise da percepção, como um todo, dos alunos e das outras pessoas que passaram pelo local, sobre o material produzido, ocorreu numa linha fenomenológica, aqui compreendida como "um procedimento para coletar dados que poderão ser abordados a partir do olhar que as pessoas têm do fenômeno observado, de modo a captar sua essência e como transcende a forma como se apresenta, postas em termos textuais" (BICUDO, 2000, p. 75). É como se pretendêssemos ver um piano em dois momentos, um piano parado, no canto da sala servindo como móvel para abrigar um pote de biscoitos e um piano, em uso, produzindo música que alegra o ambiente. Assim, o conhecimento estático a quem serve? Já o conhecimento como prática social serviria, assim como o piano que produz musica, como ferramenta para construção da cidadania. Três momentos fundamentam uma investigação fenomenológica: o olhar atentivo para o mostrar-se do fenômeno, o descrever o fenômeno e o não se deixar levar pelas crenças pré-estabelecidas sobre a realidade do fenômeno (ROJAS et al., 2012).

A coleta de dados neste tipo de pesquisa considera o sujeito da pesquisa e os próprios investigadores. $\mathrm{O}$ fenômeno manifesta-se sob diferentes perspectivas e o sujeito descreve o que lhe é percebido como modo de obtenção de dados. Segundo Bicudo (2000), a Fenomenologia trabalha com os dados fornecidos pela descrição e vai além, analisando-os e interpretando-os.

\section{RESULTADOS E DISCUSSÃO}

Antes de pormos em discussão os dados colhidos durante a mostra, convém passarmos em revista outros pressupostos teóricos que fundamentam este trabalho, entre os quais os que apresenta Durant (2005), que compreende a alfabetização científica como sendo o que o público em geral deveria saber a respeito da ciência. Este autor defende que a difusão do seu uso deveria refletir uma preocupação acerca do desempenho dos sistemas educacionais vigentes. Isso, porque pessoas alfabetizadas cientificamente tendem, além da facilidade da leitura do mundo natural, a entender as necessidades de transformação da natureza em algo para melhorar a vida na Terra, já que perceberiam que novas descobertas tecnológicas e científicas poderiam ajudar a melhorar nossa vida. Pessoas alfabetizadas cientificamente teriam, também, o discernimento do que pode ser altamente nocivo para nossa sobrevivência e para o bem estar do planeta, se não forem bem aplicadas. 0 fato é que a alfabetização 
científica pode ser considerada como uma das dimensões da educação, tendo, por isso, o condão de demonstrar seu comprometimento político e ideológico em favor de uma vida mais autônoma e saudável.

Pensando desse viés, o ensino de Ciências tem um papel significativo, já que a ciência é uma linguagem para facilitar a leitura do meio que nos cerca. Isso facilita o entendimento de nós mesmos e do ambiente em que vivemos. Propiciar o entendimento dessa linguagem seria fazer alfabetização científica e gerar, portanto, inclusão social. Ao profissional de educação cabe divulgar de forma esclarecedora o complexo que circunda os conteúdos curriculares. Para a alfabetização científica ser tema presente e passível de intermédio na construção da postura crítica dos discentes, faz-se necessário que os professores consigam a ela atribuir sentido, demonstrando a aplicabilidade dos conteúdos escolares.

0 conhecimento científico é reconstruído para se encaixar em situações concretas com toda a sua rica complexidade (ou para ser rejeitado, se não for possível). Compreender esse processo geral de contextualização é crucial para entender a autoridade social (ou a falta de autoridade) da ciência. (WYNNE, 2005. p. 30)

O conhecimento científico passa, assim, de um saber abstrato para um saber que capacita o sujeito social a propor uma intervenção e mudança social, saber palpável, presente no cotidiano. Entretanto, conforme já ficou dito na introdução deste trabalho, existem algumas dificuldades que se constituem em obstáculos à popularização da ciência (EPSITEN, 2002). Para a maior parte da população, a realidade da ciência é aquela apresentada pelos meios de comunicação em massa. 0 público, em geral, conhece a ciência menos por meio da experiência direta ou educação prévia do que por meio do filtro da linguagem e da imagética do jornalista.

Para Wynne (2005), uma implicação prática óbvia é que as instituições científicas e determinadoras de políticas que querem integrar a ciência à vida do público leigo devem estar organizadas de forma a entender e a se relacionar melhor com a hierarquização das preocupações e os conhecimentos do público. Promover a divulgação científica sem cair na simplificação das informações científicas e tecnológicas, favorecendo uma cultura científica que permita que o público, em geral, argumente sobre ciências, com o mínimo de noção sobre os processos e implicações da ciência no cotidiano das pessoas, certamente, é uma tarefa 


\section{Ensino de Ciências e Matemática Mostra cultural para divulgação científica no ensino fundamental}

árdua, a qual requer o enfrentamento de desafios constantes para alcançar certa responsabilidade social. Foi o que tentamos com esse trabalho, cuja proposta era organizar um painel e compor uma mostra cultural sobre História da Ciência. Durante os dois primeiros trimestres letivos do ano de 2011, os alunos participaram de aulas teóricas sobre os temas referentes aos conteúdos de Química e de Física, na disciplina de Ciências para o nono ano do ensino fundamental (cabe lembrar que esses assuntos como são de praxe na escola, também são articulados nas outras séries do ensino fundamental. Entretanto, o foco maior acaba sendo no último ano dessa etapa de ensino). Além disso, vários recursos metodológicos foram empregados para explorar os assuntos (vídeos, pesquisas na Internet, filmes, entre outros). Os estudantes foram, então, divididos em grupos de no máximo quatro alunos e as equipes ficaram responsáveis por estudar a história de determinado cientista (onde ele nasceu, como ele vivia, como era o seu trabalho, a importância para a época de determinado conhecimento científico produzido por ele, as suas principais contribuições para a ciência, entre outros assuntos que deixamos livres para que os alunos pudessem realmente colocar nos paineis as informações que julgassem ser interessante para os outros jovens da escola). Então, os grupos de trabalho ficaram com a responsabilidade de montar um painel explicativo sobre o pesquisador e expor na Mostra Cultural da unidade de ensino (Figura 1).

Figura 1. Painel da Mostra Cultural pronto. Fonte: Dados da pesquisa.

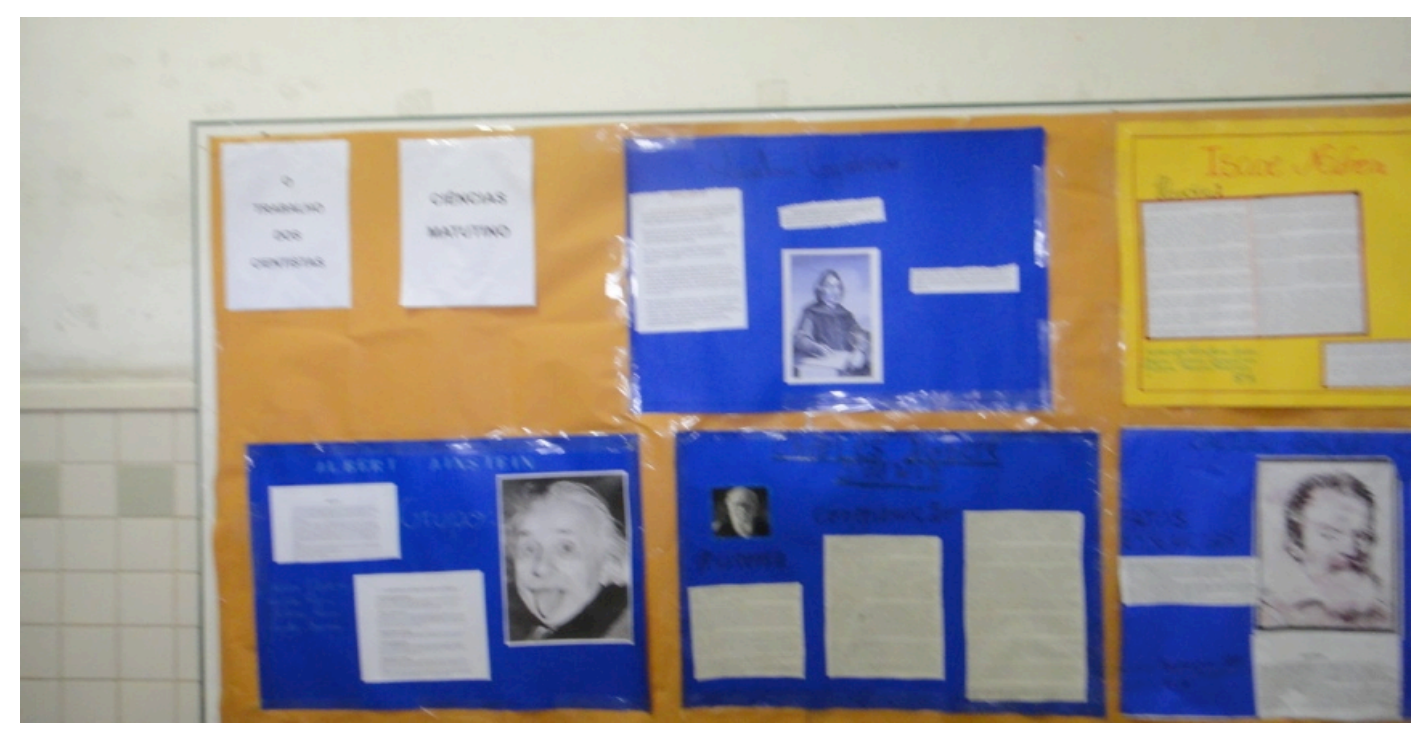

Fonte: Dados da pesquisa. 
Somaram-se em sete os cientistas escolhidos pelos alunos, todos, de alguma maneira, relacionados com algum assunto estudado por eles durante os primeiros meses do ano letivo. Foram eles: Issac Newton, Galilei Galileu, Nicolau Copérnico, Albert Einsten, John Dalton, Dmitri Mendeleev e Lavoisier. Fundamentados em Nascimento (2010, apud CARVALHO, 2010, p. 39), defendemos que a História da Ciência seria, pois, uma forma de apresentarmos aos estudantes uma ciência dinâmica e viva, discutindo a construção desde sua gênese, até chegarmos a sua concepção atual, sem nos esquecermos que essa mesma ciência pode estar sujeita a alterações no futuro. A atividade foi bastante criativa e envolveu demais os alunos no processo de ensino e de aprendizagem (Figura 2). Os alunos ficaram muito empolgados com a realização do trabalho, principalmente na hora da apresentação dos painéis para outros atores escolares, tanto que até montaram crachás de identificação. Neste ano (2012), a turma da oitava série já está cobrando do professor responsável pela disciplina de Ciências a repetição da atividade, todavia, com algo diferente do que os colegas organizaram. Essa postura representa uma forma critica de ressignificar uma prática educativa. Percebemos também uma mobilização por parte da comunidade escolar, já que o painel foi um dos mais visitados durante a realização do evento. Acreditamos que isso tem haver com o fato de que a maioria acredita que o trabalho dos cientistas está longe da nossa realidade e a tarefa executado contribuiu, de certa forma, para desmistificar um pouco essa teoria, ou seja, quebrar esse estigma.

Figura 2. Alunos durante a exposição dos paneis na Mostra Cultural.

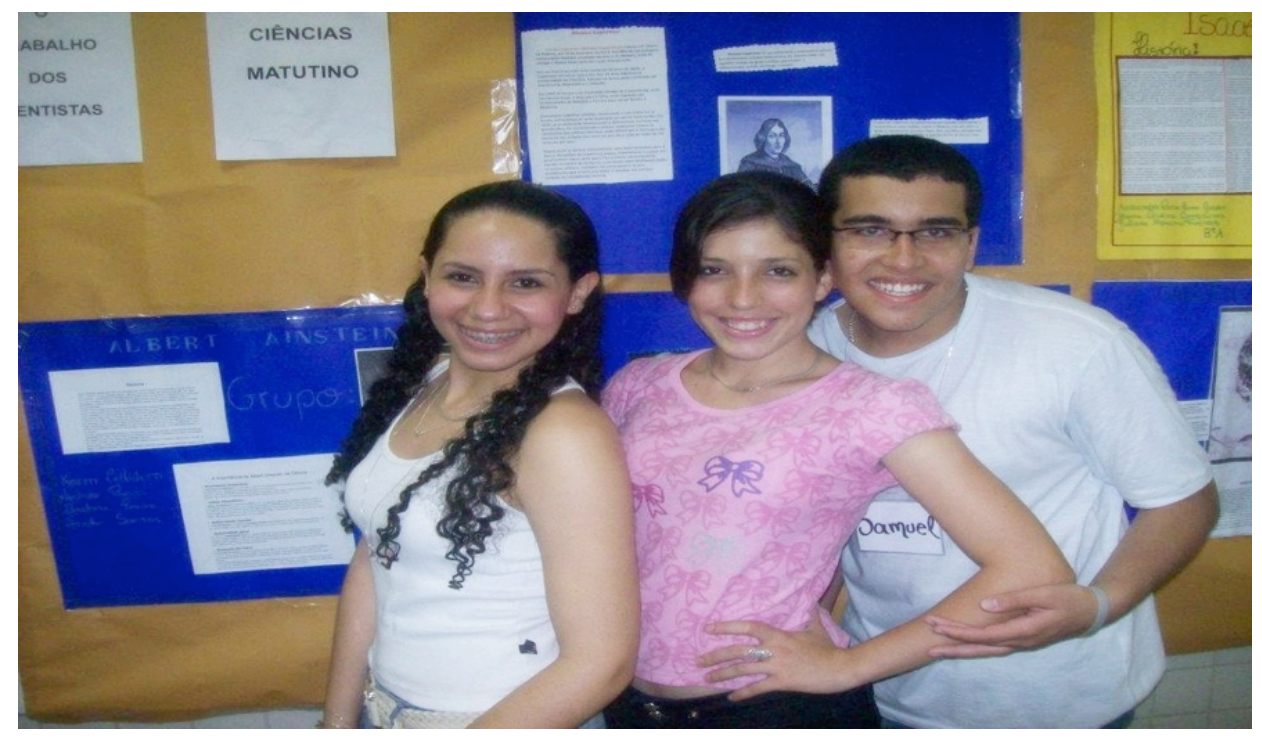

Fonte: Dados da pesquisa. 
Esse tipo de observação, colhida no decorrer da exposição dos trabalhos dos alunos, vai ao encontro do que nos diz Carvalho (2010),

\begin{abstract}
Para que ocorra uma mudança na linguagem dos alunos - de uma linguagem cotidiana para uma linguagem científica -, os professores precisam dar oportunidade aos estudantes de exporem suas ideias sobre os fenômenos estudados, num ambiente encorajador, para que eles adquiram segurança e envolvimento com as práticas científicas (CARVALHO, 2010, p. 9).
\end{abstract}

Conhecer o passado histórico e a origem do conhecimento pode ser um fator motivante para os estudantes, pode fazer com que eles percebam que a dúvida encontrada durante a aprendizagem de um conceito também foi encontrada, em outro momento histórico, por um cientista hoje reconhecido (NASCIMENTO, 2010, p. 40, apud CARVALHO, 2010). Isso é importante para que os alunos percebam que a ciência tem limitações, é falível e que não é a dona da verdade absoluta.

A sensação de que o conhecimento científico é verdadeiro, imune a questionamentos, e distante das demandas da população geral ainda se constitui uma representação social bastante enraizada em nossa população (KRASILCHIK e MARANDINO, 2007, p. 35). É notório, também, que muitas pessoas ainda possuem uma representação de que o cientista é aquele indivíduo que vive enclausurado dentro de um laboratório, com cabelo despenteado, usando um jaleco branco. Isso faz com que a ciência se afaste do cidadão comum e seja colocada em um patamar indicador de que ela é para poucos. Com essa atividade, acreditamos ter quebrado esse preconceito de que o cientista é alguém distante da realidade e que, um dia, caso seja da vontade deles, os próprios alunos poderão contribuir para a sociedade com a produção de novos conhecimentos científicos.

Por fim, para ampliar a compreensão pública da ciência devemos ter maior conscientização, ampliando o debate sobre as formas institucionais, nas quais o conhecimento científico é produzido. Não é ampliando o quantitativo de conhecimento a ser veiculado que iremos produzir cidadãos alfabetizados cientificamente, mas é mostrando os processos de produção do conhecimento. Uma forma de popularizar a ciência seria, portanto, falar de como 
determinado conhecimento é criado, ou seja, é essencial dizer o contexto no qual aconteceu certo fato, já que decidir qual a informação básica para viver no mundo moderno é hoje uma obrigação para os que acreditam que a educação é um poderoso instrumento para combater e impedir a exclusão (KRASILCHIK e MARANDINO, 2007, p. 16).

\section{CONSIDERAÇÕES FINAIS}

Este artigo teve o objetivo de destacar como a mostra cultural pode contribuir para a divulgação científica em suas diversas formas de expressão e público. A ideia era destacar que a popularização da ciência precisa de deixar de ser um fim em si mesma e adquirir o significado de um direito do cidadão e uma condição sine qua non para que o ator social consiga interagir com o mundo. Isso é essencial quando percebemos os altos índices de analfabetos funcionais e alienados cientificamente existentes na população brasileira. Nesta mostra, além dos alunos houve a presença de outros atores sociais, como professores, funcionários da escola e até um pai de aluno que demonstrou a valor do processo histórico de construção do conhecimento.

A conscientização do cidadão tem influência direta sobre a dinâmica da comunidade científica. A atualização dos temas deve permitir que os que visitam uma mostra ou exposição consigam perceber o processo de produção do conhecimento de modo nao tendencioso, permitindo o visitante a formar sua opinião. Quando o visitante vivencia o conhecimento, por meio dos recursos estéticos da mostra, ele pode se maravilhar e despertar suas emoções que vão determinar a busca permanente do conhecimento. A forma como o conhecimento apresenta para os alunos vai comandar a relação sensorial deste aluno com a ciência. Se de modo prazeroso, o ator social pode desenvolver o prazer e o sabor pela ciência. Não é preciso ser cientista para gostar da ciência, defendemos que a experiência com atividades de divulgação é que vai comandar a interlocução dos alunos e do cidadão com a ciência durante sua existência. Esperamos ter atingido este propósito, ainda que de forma modesta, e ter conseguido levar os alunos a uma reflexão sobre a função da ciência em nossas vidas.

\section{AGRADECIMENTOS}

Agradecemos aos alunos de 2011 da EMEF Marieta Escobar por sua valorosa colaboração na execução deste trabalho. Ao Diretor da Unidade de ensino (Prof. Alexandre), à coordenação de turno (Sra. Valéria) e à pedagoga do turno matutino (Sra. Andréia), sempre muito 
colaborativas para a aquisição dos materiais necessários à montagem dos painéis. Agradecemos também ao Prof. Sidnei Quezada pelo incentivo à realização deste trabalho.

\section{REFERÊNCIAS}

AUGUSTINE, N. What we don't know does not hurt us. Science, v.279 n.5357 p.1640-1641, 13 mar. 1998.

BARDIN, L. Análise de conteúdo, 3. Ed. Lisboa: Edições 70, 2004.

BICUDO, M. A. V. A contribuição da fenomenologia à educação. In: BICUDO, M. A. V.; CAPPELLETTI, I. F. (Org.) Fenomenologia: uma visão abrangente da educação. São Paulo: Olho d"Água, 1999, p. 11-51.

CARVALHO, A. M. P. Critérios estruturantes para e ensino das ciências. In: CARVALHO, A. M. P. (org). Ensino de Ciências: Unindo a pesquisa e a prática. São Paulo: Cengage Learning, 2010.

DURANT, J. O que é alfabetização científica. In: MASSARANI, L; TURNEY, J; MOREIRA, I. de C. (Org.). Terra incógnita: a interface entre ciência e público. Rio de Janeiro: Vieira \& Lent, 2005. p. 13-26.

EPSTEIN, Isaac. Divulgação Científica. 96 verbetes. Campinas: Pontes, 2002.

KRASILCHICK, M; MARANDINO, M. Ensino de Ciências e Cidadania. 2 Ed.. São Paulo: Editora Moderna, 2007.

LÜDKE, M.; ANDRÉ, M. E. D. A. Pesquisa em educação: abordagens qualitativas. São Paulo: EPU, 1986.

NASCIMENTO, V. B. A natureza do conhecimento científico e o ensino de Ciências. In: CARVALHO, A. M. P (org). Ensino de Ciências: Unindo a pesquisa e a prática. São Paulo: Cengage Learning, 2010.

ROJAS, J.; BARUKI, R.F.; SOUZA, R. S.E. Fenomenologia e rigor na pesquisa educacional: a experiência da UFMS. Anais do IV SIPQ, 2012 p. 1-10.

VOGT, C. De ciências, divulgação, futebol e bem-estar cultural. In: PORTO, C.; BROTAS, A. M.; BORTOLIERO, S. T. Diálogos entre ciência e divulgação científica. Salvador: UFBA, 2011.

WYNNE, B. Saberes em contexto. In: MASSARANI, Luisa; TURNEY, Jon; MOREIRA, Ildeu de Castro (Org.). Terra incógnita: a interface entre ciência e público. Rio de Janeiro: Vieira \& Lent, 2005. p. 27-39. 